\title{
Efectos multidimensionales de la minería en San José del Progreso, Oaxaca
}

\author{
Multidimensional Effects of Mining \\ in San José del Progreso, Oaxaca
}

\author{
Aleida Azamar Alonso* (D) http://orcid.org/0000-0002-7915-7611 \\ Isidro Téllez Ramírez ${ }^{\star *}$ (D) https://orcid.org/0000-0002-1470-0994
}

\section{Resumen}

Objetivo: categorizar los efectos sociales, culturales, ecológicos, legislativos y económicos del extractivismo minero en el ejido San José, ubicado en el municipio de San José del Progreso, Oaxaca. Metodología: consiste en una categorización multidimensional sobre los impactos de la minería en una comunidad rural. Resultados: se constató la existencia de efectos negativos multidimensionales que causó la actividad minera entre 2006 y 2019 y que afectaron a la población y al territorio. Limitaciones: la falta de presupuesto para ampliar su alcance, así como los riesgos de seguridad debido a las tensiones territoriales que existen en el lugar. Valor: la propuesta metodológica de análisis y categorización de los impactos del extractivismo. Conclusiones: se concluye que el proyecto minero San José carece de mecanismos necesarios para beneficiar el desarrollo social local.

Palabras clave: extractivismo; éxito empresarial; daños socioambientales; Compañía Minera Cuzcatlán; San José del Progreso; Oaxaca.

\begin{abstract}
Objective: to categorize the social, cultural, ecological, legislative and economic effects of mining in San José's share land, of San José del Progreso municipality. Methodology: multidimensional categorization on the impacts of mining in a rural community. Results: mining activity during the 2006-2019 period caused multidimensional negative effects, which affect population and the territory. Limitations: the lack of budget to expand its scope, as well as the security risks due to the local territorial tensions. Value: the methodological proposal of analysis and the categorization of the impacts of mining. Conclusions: the San José mining project lacks the necessary mechanisms to benefit local social development. Keywords: mining; business success; socio-environmental damage; Compañía Minera Cuzcatlán; San José del Progreso; Oaxaca.
\end{abstract}

Cómo citar: Azamar Alonso, A., y Téllez Ramírez, I. (202I). Efectos multidimensionales de la minería en San José del Progreso, Oaxaca. región y sociedad, 33, el47I. doi: I0.22I98/rys202I/33/I47|

*Autora para correspondencia. Universidad Autónoma Metropolitana, Departamento de Producción Económica. Calzada del Hueso 1100, Col. Villa Quietud, Alcaldía Tlalpan, C. P. 04960. Ciudad de México, México.

Correo electrónico: gioconda15@gmail.com

** Universidad Nacional Autónoma de México, Instituto de Geografía, Departamento de Geografía Económica. Circuito Exterior de Ciudad Universitaria, s. n., Alcaldía de Coyoacán, C. P. 04510. Ciudad de México, México. Correo electrónico: isidrotr@gmail.com

Recibido: 3 de abril de 2021

Reevaluado: 4 de agosto de 2021

Aceptado: 22 de octubre de 2021

Liberado: 26 de noviembre de 20211

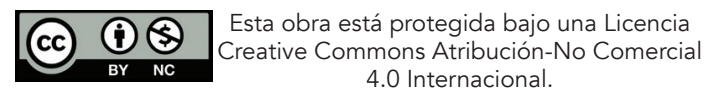

https://regionysociedad.colson.edu.mx:8086/index.php/rys/index 


\section{Introducción}

La presente investigación se realizó partiendo del interés de comprender los problemas y las relaciones en los ámbitos político, humano, económico, cultural y ecológico derivados de la minería metálica subterránea del ejido San José, ubicado en el municipio de San José del Progreso, Oaxaca. El trabajo busca aportar un marco de análisis sobre los efectos multidimensionales de esta actividad que se presentan a escala local, pues si bien hay una profusa literatura al respecto (Hernández, 2014; OXFAM, 2018; Valladares, 2018; Villavicencio, 2013), en general los trabajos se centran en analizar una sola de las cuestiones, ya sea la política, la humana, la económica, la cultural o la ecológica. En este artículo, en cambio, se abordan todas las anteriores.

La interrogante que guía esta investigación es: ¿cuáles son las implicaciones multidimensionales que se presentan en una comunidad con alto grado de marginación y pobreza debido al establecimiento de un proyecto minero intensivo y exitoso en términos empresariales? Para responder a esta cuestión, se revisa el caso de la unidad minera San José, ubicada en el ejido con el mismo nombre. Se trata de una mina subterránea que opera desde 2006 la Compañía Minera Cuzcatlán, Sociedad Anónima de Capital Variable, filial de la corporación canadiense Fortuna Silver Mines. En la actualidad, está posicionada entre las veinte principales productoras de plata del mundo, con un importante activo que tiene posibilidades de crecer.

Es importante mencionar que este caso en particular sobresale porque el proyecto minero se ubica en una entidad que no es de tradición minera. Por eso muestra bien cómo se permite cada vez más la apropiación de ciertos territorios por parte de las empresas. También es relevante por la pobreza que existe en el estado, aun cuando la actividad minera debería traer bonaza económica. Por otra parte, está la profunda violencia que ha sufrido la población que se opone a dicho proyecto.

El trabajo se divide en tres apartados. En el primero se aborda la conceptualización del extractivismo y los antecedentes de la minería en América Latina y en México. Además, se mencionan algunos datos importantes de la minería en Oaxaca y en San José del Progreso. En el segundo apartado se presenta la taxonomía de los ámbitos donde influye de forma negativa el extractivismo minero -social, político, cultural, económico y ecológico-, los cuales se analizan en el contexto de San José, Oaxaca. En el tercer apartado se consignan los resultados y se demuestra que la minería no ha representado ningún bienestar socioeconómico en dicho lugar, además de que ha implicado una gran cantidad de efectos negativos en varias dimensiones dentro de la comunidad. Al final se presentan las conclusiones.

\section{Conceptualización del extractivismo}

Respecto a los conceptos relevantes en este trabajo, se puede señalar que uno de los más recurrentes es el extractivismo, el cual ha sido utilizado común- 
mente en la literatura agroforestal desde la década de 1990 en relación con los procesos de recolección y extracción de recursos silvestres por parte de comunidades indígenas o campesinas para fines de autosustento y comercialización, aunque no sólo económica (Borgtoft y Baslev, 1993; Dufor, 1990; Ruiz, Sayer y Cohen, 1993).

Esta perspectiva, que sigue siendo relativamente común en el análisis sociológico de pequeñas agrupaciones humanas de América Latina que dependen de los ciclos naturales de la tierra para su supervivencia, ha cambiado para enlazar la categoría del extractivismo a los procesos de movimientos socioterritoriales en rechazo al aprovechamiento industrializado de la naturaleza (Svampa, 2019).

Gudynas (2009) ha propuesto una de las definiciones más comunes del extractivismo moderno. De acuerdo con el autor, es un modelo productivo asociado con las economías en vías de desarrollo para la extracción de grandes volúmenes de recursos naturales, a fin de que sean exportados hacia países industrializados sin pasar por procesos de transformación.

Sin embargo, una gran cantidad de autoras y autores ${ }^{1}$ han adaptado dicha cuestión a la realidad en la que se analiza este enfoque. Por mencionar a algunos: Alberto Acosta, Héctor Alimonda, Clara Algranati, Aleida Azamar, Claudia Composto, Sebastián Gómez, Florencia Mezzadra, Emilio Taddei, Carlos Rodríguez, José Seoane, Maristella Svampa han dado diversas perspectivas, entre las que se destacan las relaciones de poder, las economías de enclave, la acumulación y la reproducción del capital, la presión política externa, la apropiación, la violencia y otros aspectos que responden a las problemáticas específicas de las regiones que estudian.

Por otro lado, vale la pena subrayar que el aprovechamiento intensivo de la naturaleza para su posterior comercialización en los mercados internacionales es una parte fundamental de la economía contemporánea. Los procesos extractivos, como la agroecología intensiva, la explotación petrolera y la minería, se presentan como un fenómeno multidimensional que ha requerido una perspectiva de análisis amplia para observar sus efectos negativos. Por ejemplo:

1. Los procesos de despojo que privatizan espacios comunes, con lo cual se limita la libertad de tránsito, la vida y el desarrollo de las personas (Gudynas, 2017; Svampa, 2019).

2. La monopolización territorial y de los bienes que se pueden obtener de la naturaleza (Svampa, 2019).

3. El desplazamiento de los individuos de los espacios donde se desarrolla el extractivismo (Global Witness, 2020).

4. La presión económica de las empresas de este giro que coaccionan al Estado para que imponga una estructura reguladora laxa que permita múltiples riesgos (Azamar, 2019).

1 A fin de profundizar en el concepto de extractivismo, véase el trabajo mencionado de Gudynas (2009) y Gudynas (2015 y 2018). Véanse también Azamar (2017 y 2019) y Svampa (2019), que proponen una discusión sobre el concepto y su pertinencia actual. 
5. La criminalización de la defensa popular del territorio (Toledo, 2015; Zaremberg, Guarneros, Flores y Torres, 2019).

6. Los beneficios económicos que produce la minería son exiguos en comparación con los problemas provocados (Azamar, 2019; Téllez y Azamar, 2021).

7. La violencia de género que provoca esta actividad contra las mujeres cercanas a los proyectos (Azamar y Olivera, inédito; Zaremberg, Guarneros, Flores y Torres, 2019).

Estos aspectos son sólo unos pocos de entre los muchos que se pueden detectar cuando se analiza cada proyecto extractivo. Para la comprensión precisa de este fenómeno, es fundamental identificar y ordenar los problemas para operacionalizarlos y contrastarlos después. En este artículo se pretende realizar un primer esfuerzo metodológico de observación, identificación y ordenamiento del extractivismo minero.

La industria minera se orienta a la explotación intensiva de los recursos naturales mediante procesos de desterritorialización (a menudo violentos) que también criminalizan la protesta. Tiene nulo o limitado impacto económico local. Sin embargo, el Estado la respalda a través de flexibles políticas ambientales y tributarias. Su finalidad última es ampliar las capacidades de producción de los núcleos estructurales económicos mundiales que se encuentran en las naciones desarrolladas a través de la comercialización de materias primas en los mercados internacionales que dominan los oligopolios.

La minería, en cuanto que actividad extractiva, ha mantenido una importante presencia en varias naciones de América Latina, a pesar de que sólo en unos pocos países de la región tiene una aportación importante al producto interno bruto (PIB). Sobresalen los casos de Brasil, Chile, Perú y México: aunque en general desde 2012 el crecimiento del sector se ha desacelerado, hay que hacer la salvedad de que en 2021 tuvo un repunte que respondió en esencia a la recuperación de las cadenas productivas mundiales (Comisión Económica para América Latina y el Caribe-Bases de Datos y Publicaciones Estadísticas [CEPALSTAT], 2021).

Es importante señalar que este conjunto de países latinoamericanos participa con $5.7 \%$ del total de las exportaciones mundiales en minerales (metálicos y no metálicos), pero los ingresos comerciales de todas las operaciones de este sector representan más de $20 \%$ de las percepciones globales que obtuvo esta industria entre 2000 y 2019 (Comisión Económica para América Latina y el Caribe [CEPAL], 2019). Es decir, América Latina se ha convertido en una de las regiones más importantes en términos comerciales para el extractivismo.

En el caso de México, la situación del sector ha llamado la atención internacional de los empresarios mineros, pues se ha eliminado la Subsecretaría de Minería, organismo especializado en la atención y revisión de aspectos concernientes a esta actividad. Así mismo se ha limitado la cantidad de concesiones en el sexenio de 2018 a 2024, como ha señalado el presidente López Obrador desde el comienzo de su gestión (Secretaría de Economía [SE], 2021; Servicio Geológico Mexicano [SGM], 2020). No obstante, los recientes descubrimientos de litio en el estado de Sonora -el cual se ha revelado con probabilidad de ser 
uno de los yacimientos más grandes del mundo- han provocado un cambio en la apertura a la inversión productiva minera. La situación de esta industria en México tiene un historial tan largo de conflictos, accidentes e impactos negativos, ${ }^{2}$ que es necesario analizarla aún más en detalle.

\section{Diagnóstico minero en México y sus percances}

Entre todas las formas de extractivismo, una de las más problemáticas - por sus efectos negativos socioambientales- es la minería. En México aporta a la economía nacional entre $4 \%$ y $5 \%$ del PIB, dependiendo del tipo de actividad minera al que se haga referencia. ${ }^{3}$ Las concesiones otorgadas corresponden a entre 20 y 21 millones $^{4}$ de hectáreas reservadas para exploración o explotación -lo que equivale a $11 \%$ del tamaño del país- durante periodos que pueden ir desde cincuenta hasta cien años. Hay que añadir que la minería atrae una gran cantidad de inversión: cerca de $20 \%$ de la inversión extranjera directa (IED) en 2019 se concentró en este sector (SGM, 2019).

Por otra parte, más de 1200 proyectos mineros en diferentes etapas (producción, prospección, exploración) han dado lugar a 1672 minas, que en su mayoría se encuentran en los estados del norte de la nación, sobre todo en Sonora, Chihuahua, Sinaloa y Durango. De estos proyectos, cerca de novecientos tienen en común que están financiados casi en su totalidad con capital extranjero, 65\% del cual es canadiense. El resto se distribuye entre Estados Unidos, China, otros países europeos y, por supuesto, capital nacional (Azamar, inédito; SE, 2018; SGM, 2020).

Esto es grave en términos tributarios, pues los ingresos fiscales que se han obtenido del sector minero durante la última década han sido casi nulos, con un promedio menor a 1\% (Centro de Estudios de las Finanzas Públicas [CEFP], 2018; Secretaría de Hacienda y Crédito Público [SHCP], 2021). Hay que señalar que durante 2020 - un año de turbulencia económica que provocó millones de

2 Sólo por mencionar a algunos autores y autoras, Azamar (2017 y 2018) realiza una amplia y profuda revisión de esta situación en el país desde los inicios de este sector hasta los conflictos actuales. En el mismo tenor, Coll-Hurtado, Sánchez y Morales (2002) analizan algunas de las principales características y efectos de la minería en México destacando los riesgos. Delgado y Del Pozo (2001) profundizan en los elementos empresariales que condicionan los conflictos mineros en México. En cuanto a los informes oficiales, en el de la Secretaría de Gobernación (2013) se contrastan los procesos de las mineras canadienses en México con los de Canadá y se señalan los daños, los riesgos y los conflictos. Destacan también los informes de las actividades extractivas que ha realizado el Centro de Análisis e Investigación Fundar desde 2017, donde se recopilan los efectos. Desde el aspecto legislativo, se puede considerar la revisión de Cárdenas (2013), quien presenta de forma amplia y detallada la falta de garantías para el bienestar social en la Ley Minera de 1992.

3 De acuerdo con la Secretaría de Economía (2018), este sector, sólo en su forma de explotación y beneficio de las minas, aporta menos de $1 \%$ del PIB nacional, mientras que si se amplía la lectura a las cadenas productivas extendidas se considera que puede producir hasta $5 \%$.

4 Los datos específicos sobre esta cuestión no están del todo claros, pues la información estadística y cartográfica recuperada de fuentes oficiales se encuentra actualizada hasta 2019 con 16 millones de hectáreas (Cámara Minera de México [CAMIMEX], 2020, p. 101; SGM, 2019, p. 18) y difiere de la que han declarado al público los representantes del gobierno mexicano y de la CAMIMEX a finales de 2019 cuando señalaron que la cantidad de concesiones vigentes hasta diciembre de 2020 era de entre 20 y 21 millones de hectáreas. 
clausuras y cierres productivos a escala nacional por la emergencia sanitarialos grupos mineros más importantes del país declararon en sus informes anuales que tuvieron ganancias extraordinarias, ${ }^{5}$ mientras que sus contribuciones al Estado mexicano se mantuvieron constantes. Esta acumulación económica ha permitido que varias compañías nacionales, locales y extranjeras hayan mejorado su valoración bursátil a pesar de la compleja situación mundial, lo cual indica que los beneficios derivados de la minería se han concentrado en los actores privados.

Para lograr esos niveles de beneficio económico, han debido conjugarse varios factores: el laxo marco legislativo, la falta de una regulación fiscal adecua$\mathrm{da}$, el uso intensivo de los bienes naturales, el alto nivel de explotación laboral $y$, por supuesto, la violencia que se ejerce con impunidad contra la población.

Aunque la destrucción del tejido social debido a dicha violencia es uno de los efectos más notables de la minería, cabe señalar que también crean un vacío en la participación social, una disminución de la presencia del Estado como regulador y una carencia de contrapesos legislativos para la observación del comportamiento de las empresas. En su conjunto, esto se vincula con la coacción violenta de estructuras de poder para mermar la voluntad popular de la defensa territorial o la vigilancia de la naturaleza para evitar su mal uso.

Más de cuarenta poblaciones indígenas han sido afectadas en sus tierras sin consulta alguna a sus integrantes, aunque están protegidas por la Constitución mexicana para evitar este tipo de aprovechamiento. También la Carta Magna y las leyes e instituciones reguladoras han sido modificadas y reformadas en más de treinta ocasiones para facilitar esta práctica (Olivera, 2018; Secretaría de Desarrollo Agrario, Territorial y Urbano [SEDATU], 2017; Téllez y Azamar, 2021).

En suma, la cantidad de beneficios monetarios que se obtiene por la explotación minera carece de sentido al contrastarla con los múltiples problemas que se generan. En el país, la minería se practica en 24 estados, sobre todo en comunidades rurales donde ésta no se ha traducido en crecimiento económico ni en desarrollo de ningún tipo, pues una de las características comunes de esos espacios es la marginación y la pobreza: por lo menos en 17 de los 20 municipios mineros de oro y plata más importantes del país los niveles de pobreza y pobreza extrema se encuentran por encima de la media nacional (Azamar, 2021; Secretaría de Desarrollo Social [SEDESOL], 2021).

Como ya se ha mencionado, la minería en México es una actividad que ha provocado múltiples perjuicios sociales, ambientales y económicos; sin embargo, en ese país es un proceso productivo que ha sido promovido ampliamente debido, entre muchas otras cosas, a intereses políticos. Un caso notable es el del estado de Oaxaca, ya que es la tercera entidad más pobre a escala nacional, donde $75 \%$ de las comunidades tiene un alto o muy alto nivel de marginación

5 Sólo por mencionar un ejemplo, uno de los grupos mineros empresariales más grandes de México y del mundo, Grupo México (2019), reportó un crecimiento de 54\% de sus beneficios netos en 2019, y en 2020 su capitalización bursátil incrementó 141\%. Una cuestión parecida experimentó Fresnillo Plc, filial de Industrias Peñoles, pues en conjunto con Newmont Goldcorp aumentaron su valoración bursátil en 2020. 
social (SEDESOL, 2016), además de que su economía depende del sector de servicios, aunque tienen un alto potencial para la minería (SGM, 2019).

Esa entidad, ubicada en el sur del país, es un territorio con un alto potencial extractivo, pues sólo se ha explorado poco más de $7 \%$ de éste, aunque en la actualidad $4.9 \%$ está concesionado mediante 355 permisos para exploración y explotación. Contribuye con casi $2 \%$ del valor de producción nacional minero (SGM, 2020), lo cual la coloca en el decimosegundo lugar de veintisiete.

De acuerdo con información del SGM (2020), Oaxaca es rica en oro, plata, zinc, cobre, plomo y otros recursos no metálicos. Por otro lado, de los trece proyectos de la entidad, sólo dos se dedican a la extracción de metales, los cuales están ubicados en la región conocida como los Valles Centrales y están activos en la actualidad. El primero lo opera una filial de la megaempresa estadounidense Gold Resource Corporation, con dos unidades mineras llamadas Las Águilas -El Águila y Alta Gracia- que ocupan cerca de 55000 hectáreas y que se ubican en el municipio de San José de Gracia, en el distrito de Ocotlán. El segundo proyecto, el de San José, que ocupa 64000 hectáreas, objetivo de análisis de este trabajo, es de la filial de la canadiense Fortuna Silver Mines, una de las corporaciones mineras más importantes del mundo (véase figura 1).

Figura 1. Mapa de la Unidad San José

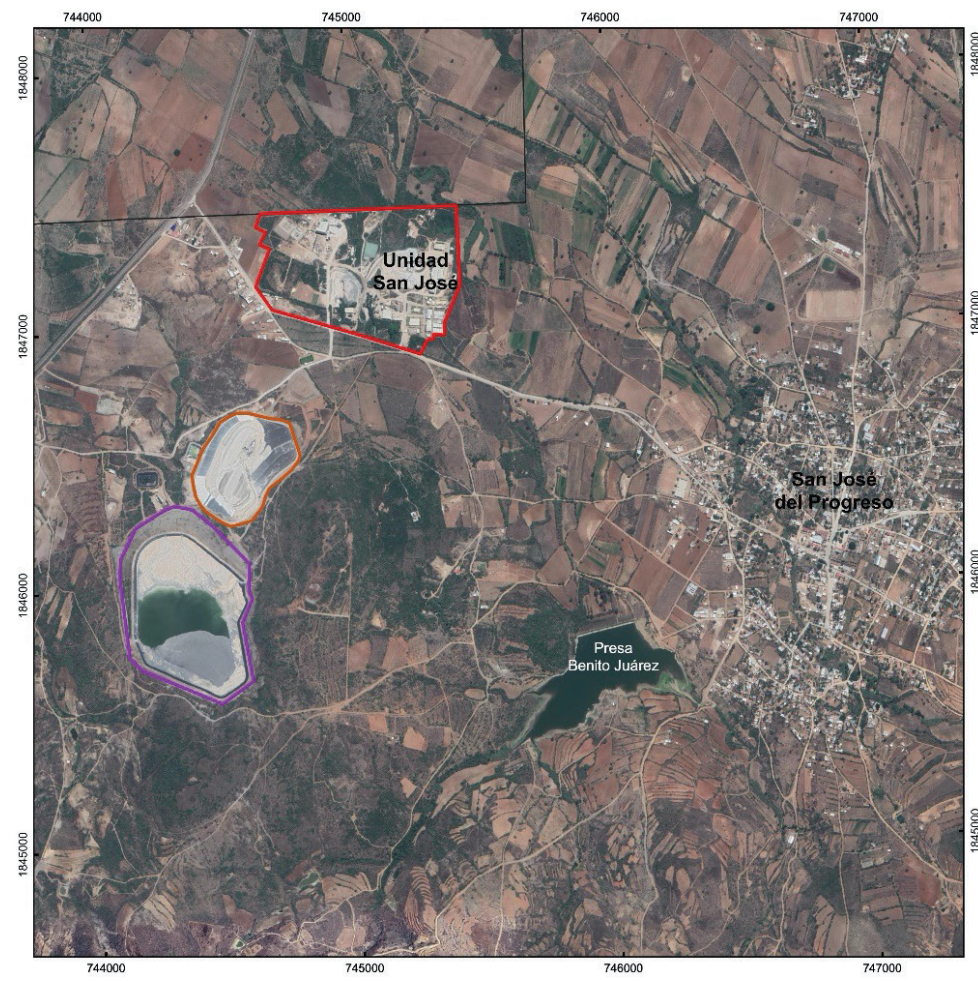

Compañía Minera Cuzcatlán Unidad San José
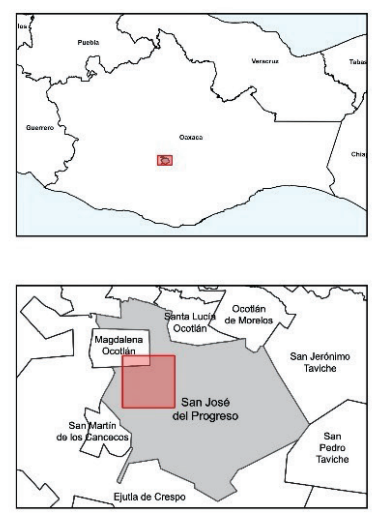

Leyenda

$\square$ Unidad San José

$\square$ Terreros

$\square$ Presa de jales

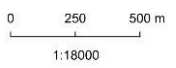

Fuente: elaboración propia (2021). 
Ambas empresas tienen $10 \%$ de las concesiones en la entidad. Procesan cerca de cinco millones de kilos de mineral al mes, para lo cual consumen entre diez y doce millones de litros de agua al día (Chapman y Sunuhaji, 2019). Además, hasta 2019 la Unidad San José contribuyó con ocho millones de onzas de plata, $5 \%$ de la producción argentífera a escala nacional, la sexta más importante del país (SGM, 2020).

Aun teniendo un evidente potencial para el sector extractivo, hay una marcada limitante en la entidad para el desarrollo empresarial que puede responder, entre muchos otros factores, al rechazo social de las prácticas extractivas debido a la violencia que causan (Colectivo Oaxaqueño en Defensa de los Territorios [CODT], 2013; Servicios para una educación Alternativa, Asociación Civil [Educa], 2017; Hernández, 2014; Oxford Committee for Famine Relief [OXFAM], 2018; Valladares de la Cruz, 2018; Villavicencio, 2013), a los riesgos socioambientales (Thaden, Robles y Fuente, 2020) y a la destrucción o apropiación del territorio (Barmeyer, 2010).

Los problemas específicos que esta actividad ocasiona en una región tan empobrecida como Oaxaca se suman a los que ya tiene el lugar. Es decir, la minería, como se ha señalado, no proporciona beneficio a la localidad, aunque para comprender la influencia concreta de ésta es necesario identificar las diferentes dimensiones en las que incide para así discriminar los aspectos que pueden revisarse en un análisis más amplio. La metodología que se propone ayuda a categorizarlos. A continuación, se profundiza en ella.

\section{Metodología}

A fin de valorar las implicaciones de este caso en particular, se requiere una aproximación multidimensional que haga referencia a las evaluaciones y análisis sociales multicriterio que fueron desarrollados en la década de 1990 para realizar observaciones y aproximaciones sobre problemas multidimensionales con resultados complejos (Martínez, Munda y O’Neill, 1998).

La multidimensionalidad se refiere a la comprensión de las expectativas y necesidades que enfrentan uno o varios grupos sociales frente a procesos de inversión que tienen impactos en el territorio. La aproximación se hace a través de varias líneas, por ejemplo, la construcción de modelos matemáticos basados en casos comparativos y el análisis de caso desde una perspectiva cuantitativa. Esta herramienta ha sido muy utilizada a escala mundial para establecer y operacionalizar valores sociales que podrían ser difíciles de determinar y comparar a través de otras técnicas de análisis (Gamboa, 2006; Garmedia y Stagl, 2010; Monterroso, Binimelis y Rodríguez, 2011).

Como principal elemento original de esta investigación, se ha partido de la necesidad que tienen los análisis multicriterio en su aspecto cuantitativo referente a la recolección de datos, por lo que se plantea un proceso de categorización de diseño propio para identificar dimensiones particulares de trabajo que permitan un análisis más eficiente. 
Con base en lo anterior, se construyó una matriz compuesta por cinco elementos generales sobre los que se articula el quehacer humano en la sociedad y sus intercambios con el medio donde se ejecuta el extractivismo: 1) institucional, 2) social, 3) económico, 4) cultural y 5) ecológico. El orden de éstos no es jerárquico; más bien es una clasificación en la que pueden incluirse diferentes aspectos dependiendo del tipo de análisis y la escala del fenómeno a revisar. Cada elemento corresponde a variables para el caso de estudio, tanto de forma documental como en campo, mediante entrevistas que se hicieron a diversos actores, pláticas formales e informales, diarios de campo y denuncias sociales contra este tipo de actividades.

La investigación se realizó entre 2018 y 2019, y su punto de partida fue la observación no participativa de dos visitas de campo a la comunidad durante los meses de julio y septiembre, respectivamente, en la cual se procuró tener la menor influencia posible sobre el actuar de los pobladores. Esta perspectiva permitió observar algunos comportamientos entre quienes están a favor y quienes están en contra de la mina, incluidas algunas actitudes de hostilidad entre ellos.

Asimismo se realizaron dieciséis entrevistas abiertas a pobladores de la comunidad, a representantes institucionales públicos y a trabajadores de la Minera Cuzcatlán. Los perfiles de las personas que participaron en las entrevistas son variados: no sólo los de los representantes comunitarios; también los de los habitantes que subsisten en estos espacios. Los aspectos que conectan entre sí a los entrevistados es que se encuentran relacionados de manera directa con la operación de la mina o que se ven afectados o beneficiados por ella. El número de entrevistas se limitó a dieciséis por cuestiones de presupuesto, tiempo y dificultad para dialogar sobre el tema sin arriesgar la seguridad propia o de quienes fueron entrevistados.

Además, se asistió a las charlas que organizaron los pobladores de la comunidad que se oponían al proyecto. En ellas se discutió el asunto de la mina y se presentaron dudas al respecto. Se encontró que una parte de los habitantes no lo apoyaba, aunque algunos coincidieron en que los ingresos económicos beneficiaban a varias familias. En general, los trabajadores estuvieron a favor de la actividad, pero se quejaron de las condiciones de inseguridad. Las pláticas colectivas en las que se estuvo presente se dieron como parte de las formas de comunicación en la comunidad y se observó que aún existe un amplio debate sobre las acciones que se deben tomar, incluso entre los que rechazan la mina.

Los datos de la empresa, de la comunidad y de la actividad minera en general se recuperaron de informes anuales de la compañía Fortuna Silver Mines Inc., de los anuarios estadísticos que publicaron la SE y la SEDESOL y de fuentes periodísticas.

A través de la metodología de análisis, se explicita cómo la monopolización territorial que produce el extractivismo forma parte de las condiciones de debilidad estructural - persistentes en el caso mencionado- que se expresan en una serie de categorías. Para demostrar lo que se ha mencionado, a continuación se 
presenta la taxonomía que se ha construido a través del tiempo de estudio en una tabla donde se muestran los principales problemas que ocasiona el extractivismo, tanto para la sociedad como para el ecosistema en diversos ámbitos.

\section{Tabla 1. Diversos impactos del extractivismo}

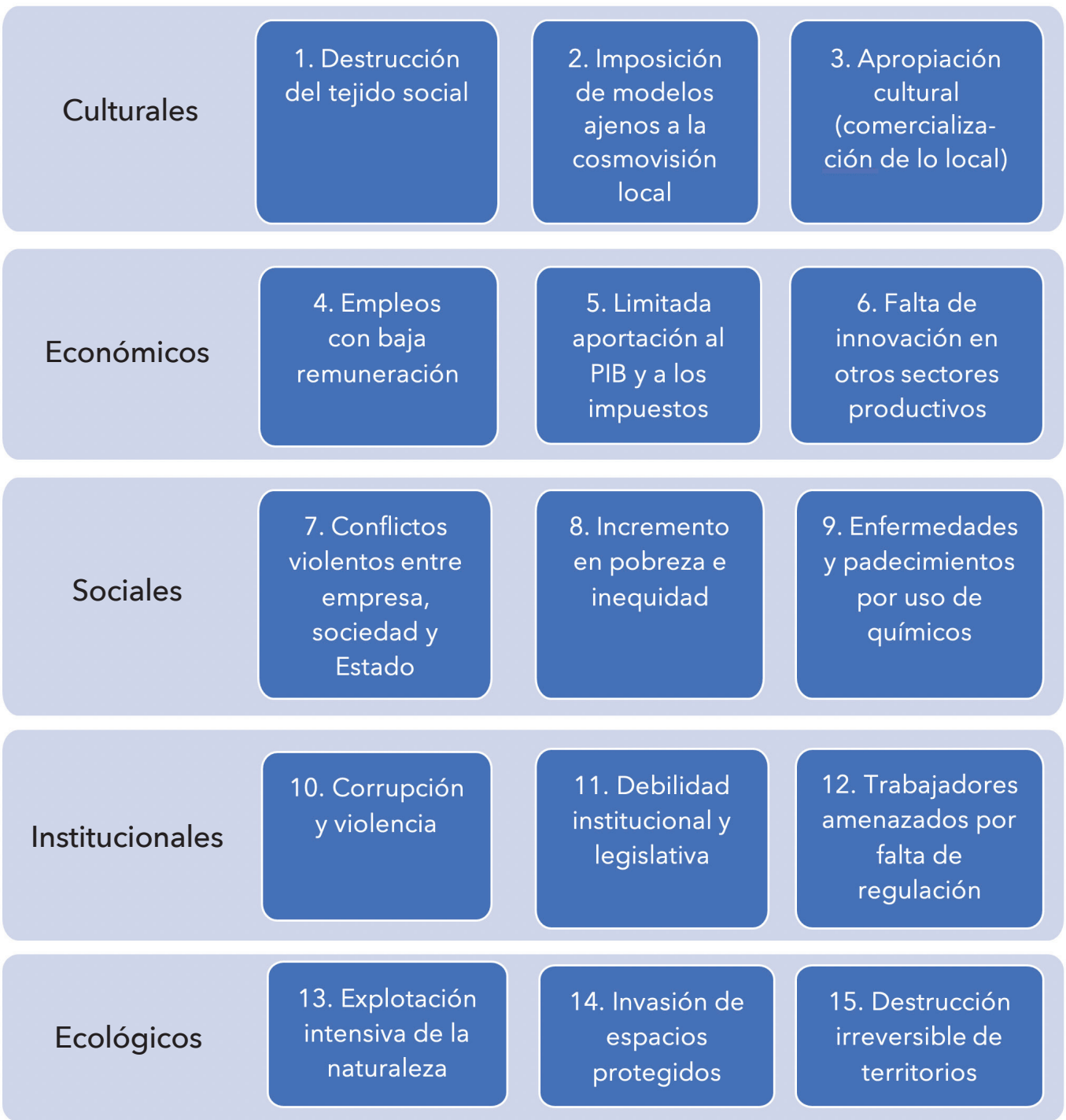

Fuente: tomado de Azamar (2015).

En la tabla 1 se señalan algunas de las implicaciones que el extractivismo tiene en diversos ámbitos para la sociedad y para el ecosistema. Aquí sólo se mencionan las que se detectaron en el caso de estudio: 1) culturales; 2) económicas; 3) sociales; 4) institucionales y 5) ecológicas. Si bien los elementos en esta tabla no se disponen en orden jerárquico, hay que advertir que existe una determinada lógica para la sucesión de estas cuestiones, pues la mayoría de las causas y subcausas están ligadas entre sí y los efectos también se relacionan. 
Las observaciones realizadas parten de un análisis cualitativo que se complementa con estadísticas de la situación en la comunidad y en el país. Respecto a las dimensiones sociales, culturales e institucionales, son más bien descriptivas por la naturaleza de la información, pero se complementan con datos de campo y también con notas periodísticas. Sobre la cuestión económica, ésta ha sido contrastada con los datos públicos y privados más actualizados disponibles, mientras que la dimensión ecológica carece de información específica debido a que las instituciones oficiales no la tienen disponible. Sin embargo, se ha cuidado que los datos recabados sean lo más completos posibles.

Por último, vale la pena mencionar que las subcategorías que contiene la tabla 1 pueden desarrollarse de forma amplia para conocer a fondo todos los elementos que la integran y sus respectivas consecuencias, pero ello requeriría mayor espacio, por lo que en este trabajo sólo se valoran los resultados de cada elemento con la intención de brindar un panorama del extractivismo minero en el ejido San José.

\section{Resultados $^{6}$}

\section{Compañía Minera Cuzcatlán y sus consecuencias}

La comunidad de San José vivió en una situación de incertidumbre desde 2006, cuando comenzó el proyecto minero, pues ni las autoridades ni los representantes de la empresa trataron de entablar diálogo previo a éste, clara muestra de la (11) debilidad institucional, ya que no se realizó ninguna consulta a las comunidades indígenas antes de llevarlo a cabo, tal como exige la Convención 169 de la Organización Internacional del Trabajo (OIT) que México ha ratificado.

Cuando llegó la mina nos empezamos a organizar para conocer lo que querían hacer con el pueblo porque nadie nos decía nada. Fue el sacerdote el único que nos explicó los problemas que provoca la mina porque ni el presidente municipal ni los dueños de la mina nos querían decir nada. (Entrevista personal, 2018)

Ante la falta de respuestas y la ausencia de apoyo del Estado, los habitantes decidieron tomar la mina para que se les respondiera y se negociara con ellos, puesto que rechazaban el proyecto.

El día que llegamos a plantarnos frente a la mina para exigir respuestas, el presidente municipal no nos quiso acompañar. Ya en la mañanita vimos cómo llegaron un montón de policías con perros y pistolas en mano; la mayoría éramos mujeres con niños, pero no nos rajamos, aunque nos llevaron presas. Yo no tenía miedo. (Entrevista personal, 2019)

6 El análisis de este caso no se realiza en orden, sino a partir de las observaciones obtenidas en campo o producto de las entrevistas, así como de la revisión de material disponible, por lo que cuando se menciona una dimensión específica se resalta en cursivas con un número entre paréntesis que la antecede, el cual puede repetirse más de una vez. 
La situación que se narra se refiere al (7) conflicto violento en el que la empresa y el Estado actuaron en conjunto en 2009 para desalojar a quienes se quejaban. Fue un grupo organizado de los pobladores de esta comunidad y de Magdalena Ocotlán el que decidió clausurar las actividades de exploración que realizaba la Compañía Minera Cuzcatlán, filial de la empresa canadiense Fortuna Silver Mines Inc., acción que provocó una respuesta violenta por parte del Estado a través del uso de la policía y el ejército para retomar el control de la zona (Villanueva, 2018). Esta situación de violencia se convirtió en una constante que llevaría a la creación de la Coordinadora de Pueblos del Valle de Ocotlán (COPUVO), que procura defender el territorio de las agresiones del Estado y de la empresa.

Nosotros nunca quisimos pleito. Fue el gobierno el que intentó callarnos y no nos dejamos. Por eso nos organizamos mejor, pero no pensamos que nos fueran a querer matar nada más por defender lo que es nuestro. (Entrevista personal, 2018)

Desde 2013 se han registrado enfrentamientos entre los grupos que están a favor y los que están en contra del proyecto, lo cual ha causado la muerte violenta de al menos cuatro personas, algunas de ellas representantes de la COPUVO o familiares de las mujeres que más lucharon para rechazar el proyecto (Villanueva, 2018). ${ }^{7}$

El Colectivo Oaxaqueño en Defensa de los Territorios (CODT) encabezó la producción del informe Justicia para San José del Progreso (2013) en el que participaron organizaciones locales e internacionales, cuatro estuvieron relacionadas con la realización del informe y quince más que se suscriben al mismo. En él se han consignado algunas de las pruebas de que la administración pública federal y la local se han posicionado a favor de la empresa y en contra de la población al emplear la fuerza pública para garantizar la actividad extractiva sin tratar de dialogar a fondo sobre el origen del problema. Además, el colectivo ha evidenciado la (10) corrupción de las autoridades, comenzando por el hecho de que no se están respetando los derechos de las comunidades indígenas a la autodeterminación y al uso de los recursos de sus territorios, derechos asentados en la Constitución, así como en otras instancias internacionales a las que el país está adscrito, cuestión que la población que rechaza el proyecto ha denunciado, tanto en las entrevistas realizadas como en otros trabajos al respecto (CODT, 2013; entrevistas personales, 2018 y 2019; OXFAM, 2018).

Por otra parte, no se han investigado los casos de acoso contra los pobladores que se oponen al proyecto. Incluso han asesinado a personas que se oponían a la mina sin que esto haya generado mecanismos de investigación y protección

7 En el blog de la organización S!Paz se ha documentado la mayoría de los enfrentamientos violentos entre la población, el Estado y la empresa. De igual forma, en el blog de la Asamblea Popular de Pueblos de Oaxaca se describen en detalle algunos de estos enfrentamientos. Por otra parte, en el informe Justicia para San José del Progreso (CODT, 2013) se documentan al menos cuatro asesinatos directamente relacionados con la oposición a la mina. Las víctimas fueron Óscar Venancio Martínez Rivera, Félix Misael Hernández, Bernardo Méndez Vásquez y Bernardo Vásquez Sánchez. En la actualidad hay otros dos casos en los que se ha perpetrado el mismo crimen sin que todavía haya evidencia de que sea específicamente por oposición al proyecto minero. 
para los inconformes con el proyecto minero (CODT, 2013; OXFAM, 2018). Así mismo la población ha denunciado las violaciones de la empresa a sus derechos y a las normas ambientales sin que las autoridades abran investigaciones (OXFAM, 2018). Esta situación ha provocado una (1) fractura en el tejido social en la comunidad de San José al debilitar o imposibilitar las formas de organización locales tradicionales, lo cual ha afectado sus modos de vida y ha ocasionado tensión, pues hay quienes, por diversas razones, han decidido apoyar el proyecto minero.

Ya tiene muchos años que no les hablo a mis primos porque disque querían trabajar en la mina. Decían que se gana mejor que cosechando. Yo primero quise convencerlos, pero se enojaron y mucha gente se empezó a juntar y a decir que nosotros estábamos mal, que nos queríamos quedar pobres. Yo creo que algunos también se juntaron por miedo. (Entrevista personal, 2018)

Las actividades productivas de la zona, que eran agrícolas por tradición, se vieron transformadas debido al conflicto entre la población y a las agresiones de la empresa. El proceso minero se (2) impone a la cosmovisión local, que, como se señala en una de las entrevistas: "Ya casi no hay fiestas. Antes todo el pueblo se juntaba para rezar, para celebrar y para trabajar. Ya no es así" (entrevista personal, 2018).

Esta situación ha provocado la separación familiar y el quiebre de los procesos de socialización más básicos en el territorio, ya que una parte del pueblo construyó otra iglesia, otro mercado y se puso en operación una compañía adicional de taxis debido al conflicto interno entre quienes están a favor de la mina y quienes están en contra de ella. El problema está tan enconado que aunque el mismo cura oficia misa en los dos lugares con un mensaje de reconciliación, la población no ha podido llegar a ningún acuerdo (entrevista personal, 2019; Villanueva, 2018).

Por otro lado, el lugar se caracteriza por el alto grado de marginación pues, de acuerdo con las cifras de SEDESOL (2016, actualizadas en 2018), 97\% de las 6822 personas que viven en el municipio carece de servicios básicos de vivienda, situación que aprovechó la Compañía Minera Cuzcatlán para conseguir el apoyo de los habitantes, que se vieron enfrentados a la disyuntiva que representaba la oferta de empleo por parte de la empresa, la cual comenzó operaciones comerciales a partir de 2011.

La suma de todas las cuestiones ha derivado en el conflicto social que ha dividido a la comunidad de San José, Oaxaca. El gobierno, en vez de resolver el problema, ha optado por edificar algunas obras civiles básicas, como centros comunitarios, y la empresa ha recurrido a la construcción del techo de escuelas y a pavimentar algunas calles (OXFAM, 2018). Estas acciones son parte de las estrategias de cooptación comunitaria que se utilizan para persuadir a ciertos actores sociales sobre los resultados "positivos" del proyecto.

Las acciones de ambos actores (gobierno y empresa) responden a la necesidad de convencer a la población de que la minería trae beneficios, aunque sus 
argumentos no coinciden con las cifras que reporta la SEDESOL, donde no se observa tendencia positiva alguna, tal como se muestra en los indicadores de la figura 2.

Figura 2. Variación anual en los indicadores de carencias para la comunidad de San José, 2010-2016 (porcentaje)

120

100

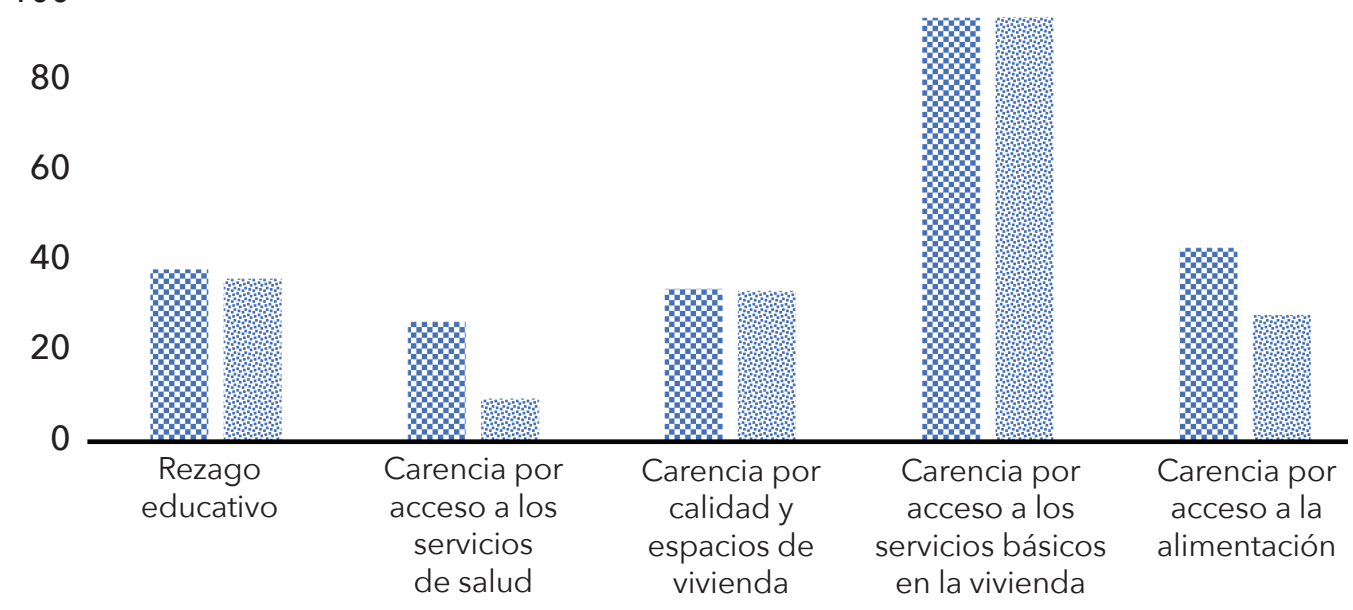

20102016

Fuente: elaboración propia con datos de SEDESOL (2010 y 2016).

Como se observa en la figura 2, entre 2010 y 2016 la variación en las carencias de esta comunidad ha sido mínima, excepto en salud y en alimentación. Las modificaciones en el resto de los indicadores no han cambiado en más de $2 \%$, por lo que están dentro del margen de error de este tipo de contabilidad estadística. Por eso se podría asegurar que no han variado en este periodo. Se observa así el (8) incremento en pobreza e inequidad por lo menos para un indicador y el mantenimiento de condiciones adversas para todos los demás.

Se debe puntualizar que aunque la carencia de acceso a los servicios de salud ha disminuido en este periodo, las dos clínicas que hay en San José del Progreso no cuentan con material ni personal adecuados para atender los problemas de salud locales. De acuerdo con información de la clínica de Servicios de Salud de Oaxaca, en la comunidad vecina de Maguey del Largo se han multiplicado (9) las enfermedades respiratorias agudas en menores de edad y trabajadores de la mina (Hernández, 2019). Esto concuerda con lo mencionado en el informe Justicia para San José del Progreso (CODT, 2013), en el que se dice que hay problemas por el ruido y el polvo que produce la mina, lo que ha ocasionado un incremento de enfermedades, sobre todo en las personas más vulnerables 
(niños, mujeres embarazadas y personas adultas mayores), así como en los (12) propios trabajadores menos especializados por la limitada protección que reciben para realizar su labor. Por otro lado, hay una gran preocupación de la población de que se les niegue la consulta o los medicamentos a los que se oponen al proyecto minero.

Un caso adicional es el de la comunidad de San Jerónimo Taviche, una población vecina a San José donde se encontraba la compañía Minerales de Oaxaca, en la actualidad cerrada, aunque en 2017 se ha vuelto a concesionar este espacio a Fortuna Silver a través de otra de sus filiales. La forma de operación de la mina era subterránea, igual que la de San José del Progreso, y los trabajadores del proyecto decían que creaba condiciones de riesgo, porque se los exponía a los gases subterráneos, al mercurio, al arsénico, al plomo, al cianuro y a algunos químicos empleados para los procesos de explotación (entrevista personal, 2018).

El modo de trabajo y la limitada protección de los trabajadores ocasionaban que inhalaran polvo de sílice, un material común en la mayoría de las minas, el cual es causante de la silicosis, una enfermedad pulmonar que provoca dificultades para respirar, así como otras molestias. Además, aumenta el riesgo de cáncer pulmonar y de otras enfermedades. Aunque los datos son anecdóticos debido a la falta de estadísticas históricas de salud, la mayoría de los trabajadores sobrevivientes del proyecto Minerales de Oaxaca señalaron que eran proclives a las enfermedades respiratorias y a otros padecimientos derivados de éstas (entrevista personal, 2019; Thaden, Robles y Fuente, 2020).

Tabla 2. Volumen de oro y plata producido en la Unidad Minera Cuzcatlán, 2011-2018 (onzas de mineral extraído)

\begin{tabular}{|c|c|c|}
\hline Año & \multicolumn{1}{|c|}{ Plata } & \multicolumn{1}{c|}{ Oro } \\
\hline 2011 & 490555 & 4622 \\
\hline 2012 & 1949178 & 17918 \\
\hline 2013 & 2527203 & 19031 \\
\hline 2014 & 4396760 & 33496 \\
\hline 2015 & 4928893 & 38526 \\
\hline 2016 & 6124235 & 46018 \\
\hline 2017 & 7526555 & 55950 \\
\hline 2018 & 7979634 & 53517 \\
\hline Total & 35923013 & 269078 \\
\hline
\end{tabular}

Fuente: elaboración propia con datos de Fortuna Silver Mines Inc. (2019). 
Este caso debería alertar sobre las afectaciones de salud en la comunidad de San José, donde los trabajadores entrevistados se quejaron de la falta de condiciones de seguridad y de equipo adecuado para laborar (entrevista personal, 2019). Además, los trabajadores que se dedican a la extracción directa del mineral también se ven amenazados en su salud por la falta de regulación productiva, pues de acuerdo con testimonios de la población, algunos mineros locales han comenzado a perder el cabello (Hernández, 2019).

Por otro lado, esta zona minera de Oaxaca ha cobrado interés e importancia internacional por su volumen productivo, ya que entre 2012 y 2018 el crecimiento promedio del volumen de la producción fue de $28 \%$ para la plata y de $22 \%$ para el oro, lo que ayudó a que la empresa se posicionara entre los mayores 20 productores de plata del mundo (S\&P Global Market Intelligence, 2019). Cabría esperarse una modificación notable en la situación que enfrenta la comunidad debido a que la empresa es muy próspera, pero sucede justo lo contrario.

Ahora bien, respecto a los elementos económicos estipulados en la tabla 1, se encuentran: (4) empleos con baja remuneración, (5) limitada aportación al producto interno bruto (PIB) y a sus obligaciones fiscales y (6) poco o nulo impacto en la innovación de otros sectores productivos. En cuanto al primer punto, empleos, es conocido que el sector minero es uno de los que mejor paga a sus trabajadores en México, ${ }^{8}$ como se observa en la figura 3.

Figura 3. Salario promedio diario de cotización entre 2009 y 2015 en el sector minero-metalúrgico y promedio nacional (pesos)

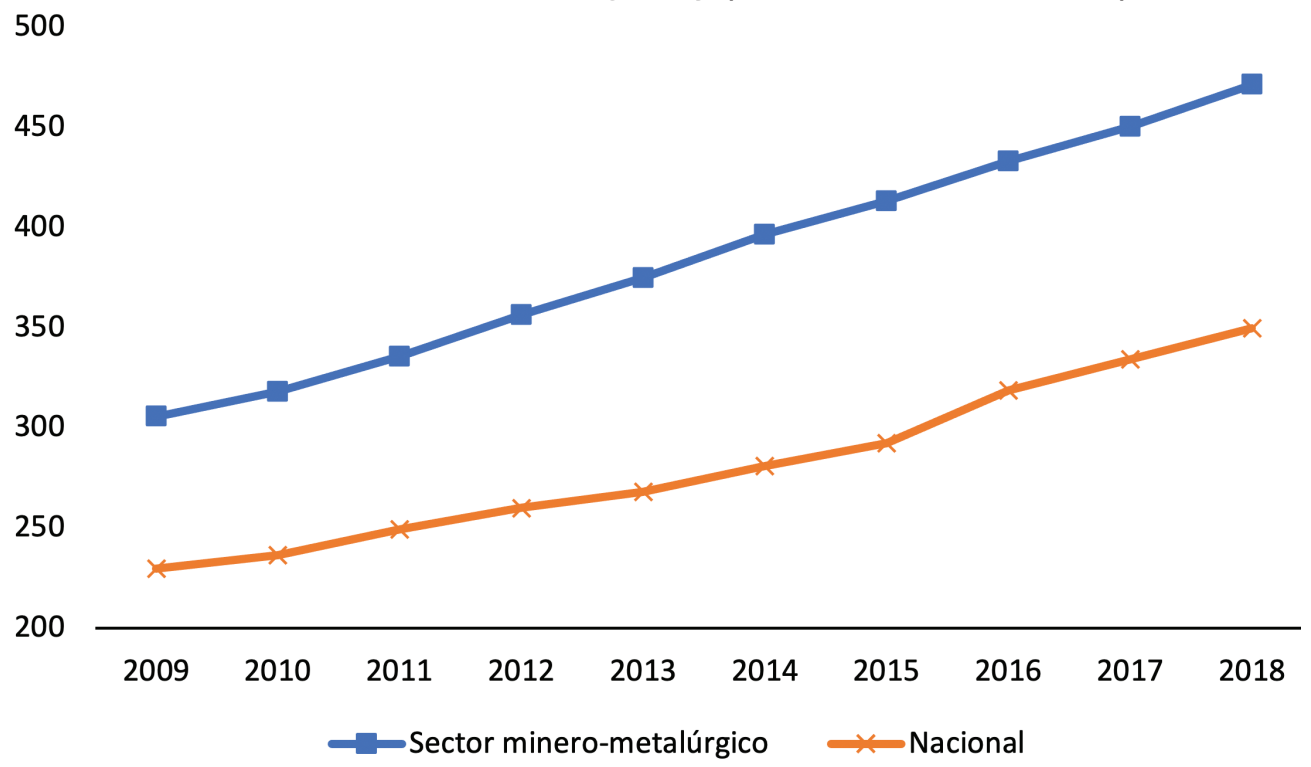

Fuente: elaboración propia con datos de Secretaría de Economía (2018).

8 Aunque en comparación con la percepción económica de los trabajadores mineros que están en nómina de Estados Unidos y Canadá, el pago es mínimo, a pesar de la importancia productiva de las minas nacionales y de los menores costos que tienen en México. Por otra parte, es importante señalar que si bien el ingreso promedio de estos trabajadores puede parecer relativamente alto en comparación con el de otros empleos en el país, lo cierto es que, para este caso en particular, los trabajadores que realizan la extracción directa tienen un salario que está dentro del promedio nacional, condicionado a una temporalidad menor debido al promedio de vida de la mina y a su vez que no corresponde a los riesgos que enfrentan. 
Es evidente que existe una notable diferencia en los ingresos de los trabajadores mineros y los que laboran en otros sectores. No obstante, debe señalarse que si se revisa la información de forma desglosada respecto a los esquemas de contratación en el sector, se descubrirá que en las últimas décadas los trabajadores por nómina han disminuido, mientras que los subcontratados han aumentado (Casado y Sánchez, 2019). Esto implica que los segundos cuentan con menores prestaciones sociales o carecen por completo de ellas (servicio médico, indemnizaciones, prestaciones para cónyuge e hijos, entre otras). Por eso las remuneraciones resultan más bajas que en los sectores que sí incluyen prestaciones. Además, se debe considerar que la minería subterránea es de las actividades más riesgosas debido a la frecuente caída de rocas, incendios y atropellamientos. Por otra parte, son los trabajadores de menor nivel ${ }^{9}$ los que tienen responsabilidades de mayor riesgo y a quienes se les retribuye en menor proporción.

Aunque no se tienen datos oficiales respecto a las retribuciones de los empleados en el caso de la Mina de Cuzcatlán, hay testimonios de personas que afirman ganar un salario promedio de entre 4800 y 6000 pesos (o sea, entre 50 y 70 dólares) al mes (Hernández, 2019), dato que se corrobora con las entrevistas realizadas, en las cuales se decía que el salario más alto no pasaba de 8000 pesos: "Yo doblo turnos y a veces gano 7500 pesos, depende de lo que me dejen hacer" (entrevista personal, 2019). Si se contrastan estos testimonios con lo que se muestra en la figura 3 (un comportamiento que debería estar generalizado en la minería a escala nacional), es probable que la media de pago identificada en la curva del sector no corresponda con la realidad de una gran parte de los trabajadores.

Asimismo, de acuerdo con los datos recuperados del informe anual de Fortuna Silver Mines Inc. (2019), el número de personas que operaba en la mina era de 986 en 2019. De éstas, 491 son personal administrativo y 495 contratistas con diferentes niveles técnicos de preparación, de los cuales la mayoría son quienes extraen el recurso y los que perciben menores remuneraciones. Por eso es muy probable que los rangos de salarios superiores (sobre todo del personal administrativo) eleven la media de remuneración, con lo cual quedaría subrepresentado el ingreso real de quienes se encuentran en el escalafón más bajo de la pirámide productiva del sector (este ejemplo se puede usar para interpretar la figura 3 de la minería a escala nacional).

Por otro lado, si la bonanza de esta empresa no está orientada a favorecer a los trabajadores por medio de los salarios que les paga, entonces se esperaría que ésta se reflejara en las finanzas del municipio o del estado de Oaxaca y no sólo en el desempeño productivo del sector sin aportar al bienestar de la entidad o de la comunidad. Sin embargo, la eficiencia de la compañía ha fortalecido el sector minero de Oaxaca, pero no ha impactado de forma positiva en el crecimiento del PIB de la entidad.

9 En forma simplificada, una mina requiere extracción, procesamiento, transporte y mantenimiento. Aunque todas las actividades tienen cierto nivel de riesgo, los trabajadores que extraen el material de las minas subterráneas hasta el exterior tienden a estar más expuestos a diversos efectos tóxicos o peligros físicos. Además, suelen ser la mayor parte de la plantilla de trabajadores activos. 
De acuerdo con datos de la Secretaría de Economía (2018), en 2010 Oaxaca se encontraba en el lugar trigésimo primero en cuanto a la aportación al sector minero, con doscientos millones de pesos mexicanos ( $\mathrm{mpm}$ ), pero en 2018 aportó $3851 \mathrm{mpm}$, cantidad que colocó a la entidad en el lugar décimo séptimo a escala nacional (el sector minero ganó mucho más que en años anteriores). Esta situación no impactó de forma positiva en la economía del estado, pues en el mismo periodo Oaxaca pasó del lugar vigésimo al lugar vigésimo tercero en el ranking económico nacional. Aunque la minería se considera un sector estratégico, no está aportando lo suficiente para fortalecer la posición de esta entidad en el panorama nacional; tampoco ayuda a frenar su descomposición económica.

De acuerdo con el informe de Fortuna Silver Mines Inc. (2019), la aportación de la empresa al Estado en forma de impuestos desde 2014 hasta 2018 ha sido de cuarenta millones de pesos en promedio y, debido a su estrategia contable, una parte de sus gastos de exploración son deducibles de impuestos. Si esto se observa como un porcentaje de los ingresos tributarios del Estado en ese mismo periodo, representaría $0.17 \%$ de éstos.

Según el Movimiento Mesoamericano contra el Modelo Extractivo Minero (2015), los beneficios económicos de la empresa fueron de 1668 mpm en 2015, por lo que el pago erogado por su beneficio fue equivalente a $2.4 \%$. En otras palabras, la aportación que esta compañía hace a las finanzas públicas es simbólica en comparación con el volumen de mineral que explota. Se puede afirmar que su aportación al PIB y a los impuestos locales es limitada.

Por otro lado, realizando un proceso de (13) explotación intensiva de la naturaleza por un aprovechamiento depredador sobre la zona donde se ejecuta un proyecto extractivo, se termina por imposibilitar la calidad operativa de otras actividades agrícolas que requieren tierra y otros bienes naturales. En este caso, como en cualquier proyecto minero, se necesita una ingente cantidad de agua proveniente de cuerpos de agua superficiales y subterráneas, así como de arroyos y presas.

La Unidad San José utiliza más o menos ocho millones de litros al día para sus operaciones, cantidad alarmante debido a la severa sequía que atraviesa el país, pues durante 2020 y hasta principios de 2021, Oaxaca ha enfrentado una situación extraordinaria en ese sentido, lo que ha provocado que no sólo los municipios cercanos a las minas estén sin agua de forma constante; también la zona metropolitana de la entidad ha experimentado cortes de hasta veinte días (Avispa Midia, 2020).

El problema principal es la intensidad con la que operan las minas en el lugar, pues además de San José y Las Águilas, hay una docena de proyectos no metálicos que también consumen una gran cantidad de este líquido.

Ahora bien, la minería es, por lo general, destructiva, sobre todo si no hay controles adecuados para su operación, en especial en zonas remotas del país, lo que conduce a la (15) destrucción irreversible del territorio, porque degrada las cadenas tróficas locales (Azamar, 2018). La Unidad San José cuenta con dos presas de jales: una de depósitos acuosos y otra para depósitos espesados, también conocida como jales secos. Para la construcción de esos espacios se 
modificaron los lugares de pastoreo cercanos a la cuenca de El Coyote, la cual también fue transformada a fin de incrementar la capacidad de las presas. Y es que los pobladores que entrevistó el OXFAM denunciaron que se atendió sólo de forma parcial la advertencia en torno a las lluvias de 2018, pues las autoridades determinaron que ocurrió un desbordamiento de la presa de jales secos hacia la cuenca de El Coyote que sólo fue "castigado" con medidas administrativas, sin existir otros apoyos de resarcimiento o mejoramiento en la seguridad. Poco después se observaron varios animales muertos en el arroyo La Chilana, a donde, se comentó, que la empresa dejó pasar parte del exceso de la presa de jales de manera intencional, pero las autoridades no hicieron mayores revisiones en ese arroyo. La falta de apoyo del Estado dificulta el análisis de este aspecto, aunque el OXFAM (2018) hace eco de un estudio realizado por Ramos, Silva y Montes (2012) que denuncia la alta vulnerabilidad de los acuíferos debido a los contaminantes de la mina.

Además de esta cuestión, desde 2010 la empresa cuenta con la posibilidad ${ }^{10}$ de verter más de tres mil litros de desechos mineros diarios en un pozo de absorción, y en 2014 obtuvo un permiso para tirar cincuenta mil litros diarios en el río Atoyac, sin que se haya realizado ningún análisis sobre el impacto que esta acción pudiera tener (Comisión Nacional del Agua [CONAGUA], 2021).

Por otra parte, el proyecto ha ido modificando el espacio. Con cada detonación de la mina, las casas han sufrido diversos problemas: quiebres de paredes y techos, por ejemplo. Además, las calles están cuarteadas por los camiones y las máquinas que transitan por ellas.

La compañía minera ha terminado apropiándose del territorio ejidal, (14) invadiendo espacios protegidos que no son áreas naturales, sino tierras pertenecientes a las comunidades y sobre las cuales sus miembros deciden qué hacer con ellas. Esto obstaculiza la independencia de la población respecto a los trabajos que ofrece la minera, ya que casi no hay otras opciones. Además, dificulta mejorar o innovar en otros sectores que fortalezcan las capacidades económicas locales, debido a que se carece de espacios para trabajar y, al dañar el territorio, se impide la posibilidad de mejorar su aprovechamiento.

Este problema afecta a los más de seis mil habitantes del municipio de San José: a estas comunidades indígenas, protegidas por la Constitución mexicana y otros acuerdos internacionales en los cuales se exige que se respete su territorio, se les niega el derecho a un ambiente sano y a un territorio libre donde puedan decidir sobre el uso y el aprovechamiento de los bienes naturales.

\section{Conclusiones}

A través de lo comentado hasta ahora por medio de los cinco elementos específicos (divididos cada uno en tres) de influencia negativa debido al extractivismo minero, podemos constatar que la extracción de minerales metálicos en esta

10 Los títulos de estos permisos son 05OAX137241/20FDOC10 y 05OAX137328/20FDDA13 y se encuentran disponibles en el Registro Público de Derechos de Agua (CONAGUA, 2021). 
comunidad ha resultado un negocio excelente para la empresa al promover su posición entre las compañías de plata más importantes del mundo y al mejorar su capacidad económica. Pero lo anterior no se ha visto reflejado en bienestar para la comunidad o el Estado.

Una de las intenciones de este ejercicio de análisis fue presentar un caso que pudiera ser más o menos común en el país debido a las varias coincidencias con el contexto minero nacional que se presentó en la sección del diagnóstico sectorial, en el que se manifestara una tendencia al empobrecimiento social para beneficiar a un sector empresarial mediante el extractivismo. Otro objetivo fue que pudiera servir de ejemplo de las cosas que las autoridades deberían revisar a fondo para frenar este tipo de proyectos y aplicar procesos de regulación más eficientes para limitar el riesgo de la práctica extractiva y proteger a los actores afectados.

Como resultado de la pregunta de investigación, se puede considerar que la situación de la población en general se ha degradado en términos de valoración cuantitativa y cualitativa respecto a los indicadores disponibles sobre la multidimensionalidad de la pobreza. De igual forma, se han afectado aspectos ecológicos, y la cohesión social se ha visto amenazada por los conflictos internos derivados del proyecto.

Si bien puede haber un repentino flujo de ingresos para la comunidad durante la existencia del proyecto, lo cual deriva de las contrataciones, lo cierto es que al finalizar el tiempo productivo de la mina existe la posibilidad de que la comunidad sea incapaz de aprovechar la bonanza transitoria y regrese a su estado previo de pobreza, con el agravante de la destrucción del ecosistema y el deterioro de sus propias relaciones sociales y productivas locales. Aunque este aspecto requiere mayor análisis, existe evidencia en otros proyectos mineros de que a largo plazo hay pocos impactos positivos derivados de estas actividades. Respecto a los efectos socioeconómicos, es importante señalar que los dueños de la Compañía Minera Cuzcatlán han optado por minimizar los costos sociales y laborales, maximizando su ingreso a costa de mantener un empobrecimiento ofensivo en San José del Progreso.

Por otro lado, uno de los muchos problemas que surgen en esta comunidad oaxaqueña debidos al proyecto minero, es que las instituciones no han garantizado la seguridad de los opositores a él, lo que se ha expresado en violencia y pérdida de vidas humanas. Se ha observado que, para el Estado, ha sido de importancia crucial mantener la actividad de la mina, lo que puede ser contradictorio debido al bajo impacto económico para el país y para los habitantes locales. Pero es que esta situación responde en esencia a la coerción externa. Por lo demás, es parte de los problemas que el extractivismo propicia.

A la luz de la información recabada, el extractivismo minero no ha favorecido el desarrollo local, económico, productivo o social y ha dañado el ecosistema. Los resultados obtenidos en este análisis muestran que esta situación se puede repetir en otras comunidades mineras del país, por lo que es necesario para futuros trabajos operacionalizar la metodología aquí expuesta en forma de indicadores comparables entre distintos casos de estudio para establecer un diagnóstico más profundo de las implicaciones multidimensionales de la minería en México. 


\section{Referencias}

Avispa Midia. (2020). Oaxaca. Minería podría agudizar sequía en pleno pico de pandemia. Recuperado de https://avispa.org/oaxaca-resiste-vs-mineria/?i$\mathrm{dU}=1$

Azamar, A. (2015). El debilitamiento del Estado a partir de las políticas extractivas en México. Ponencia presentada en el III Congreso de Sociología. Universidad de la República de Uruguay.

Azamar, A. (2017). Megaminería en México: explotación laboral y acumulación de ganancia. Ciudad de México: Editorial ITACA y Universidad Autónoma Metropolitana. Recuperado de https:// publicaciones.xoc.uam.mx/TablaContenidoLibro.php?id_libro=755

Azamar, A. (2018). Minería en América Latina y México: problemas y consecuencias. Ciudad de México: Universidad Autónoma Metropolitana. Recuperado de https://www.casadelibrosabiertos.uam.mx/contenido/contenido/ Libroelectronico/mineria_en_al.pdf

Azamar, A. (2019). Extractivismo corporativista en México: minería en Guanajuato. Revista Economía \& Sociedad, 24(55), 78-100. doi: https://doi. org/10.15359/eys.24-55.5

Azamar, A. (inédito). Perspectivas y análisis de la minería mexicana en el siglo XXI.

Azamar, A., y Olivera, B. (inédito). Extractivismo y desarrollo. Dos caras de la misma moneda: amenaza para las mujeres en América Latina.

Barmeyer, N. (2010). Guía de información para la defensa de los territorios: minería. Recuperado de http://defiendelasierra.org/wp-content/ uploads/2015/12/guia-informacion-defensa-de-los-territorios-oaxaca.pdf

Borgtoft, G., y Baslev, H. (1993). Palmas útiles. Especies ecuatorianas para agroforestería y extractivismo. Quito: Ediciones ABYA-YALA.

Cámara Minera de México (CAMIMEX). (2020). Informe de sustentabilidad 2020. Recuperado de https: / camimex.org.mx/packages/camimex/images/ Inf-Sustentabilidad-2020-Camimex.pdf

Cárdenas, J. (2013). La minería en México: despojo a la nación. Cuestiones Constitucionales (28), 35-74. doi: http://dx.doi.org/10.1016/S14059193(13)71275-7

Casado, J. M., y Sánchez, M. T. (2019). Los mineros en el México neoliberal. Investigaciones Geográficas (98), 1-20. doi: https://doi.org/10.14350/ rig. 59787

Centro de Estudios de las Finanzas Públicas (CEFP). (2018). El sector minero y su importancia en las finanzas públicas de México, 2007-2017. Ciudad de México. https://www.cefp.gob.mx/publicaciones/documento/2018/ cefp0342018.pdf

Comisión Económica para América Latina y el Caribe-Bases de Datos y Publicaciones Estadísticas (CEPALSTAT). (2021). Base de datos en línea. https:// estadisticas.cepal.org/cepalstat/portada.html 
Chapman, E., y Sinuhaji, A. (2019). Fortuna Silver Mines Inc.: San José Mine, Oaxaca, México. Technical report. Recuperado de https://fortunasilver. $\mathrm{com} /$ site/assets / files/4185/san-jose-mine-technical-report-effective-date-february-22-2019-28mar19.pdf

Colectivo Oaxaqueño en Defensa de los Territorios (CODT). (2013). Justicia para San José del Progreso. Informe de la misión civil de observación. Oaxaca, México: Colectivo Oaxaqueño en Defensa de los Territorios. Recuperado de http://endefensadelosterritorios.org/endefensadelosterritorios/2014/03/16-DE-DICIEMBRE-INFORME-web.pdf

Coll-Hurtado, A., Sánchez, M. T., y Morales, J. (2002). La minería en México. Ciudad de México: UNAM, Instituto de Geografía. Recuperado de http:// www.publicaciones.igg.unam.mx/index.php/ig/catalog/view/82/83/252-1

Comisión Económica para América Latina y el Caribe (CEPAL). (2019). La inversión extranjera directa en América Latina y el Caribe 2019. Recuperado de https: / / bit.ly/36fiDcQ

Comisión Nacional del Agua (CONAGUA). (2021). Base de datos del Registro Público de Derechos de Agua. Recuperado de https: / /app.conagua.gob.mx/ TituloRepda.aspx?Id=050AX137811/22FSDA16 |0 |3|S

Delgado, R., y Pozo, R. del. (2001). Minería, Estado y gran capital en México. Revista Economía e Sociedade Campinas (16), 105-127. Recuperado de https://www.eco.unicamp.br/images/arquivos/artigos/522/06-wise.pdf

Dufour, D. L. (1990). Use of tropical rainforests by native Amazonians: these sophisticated and complex agricultural systems can serve as models of sustainable agroecosystems. BioScience, 9(40), 652-659. doi: https://doi. org / 10.2307/1311432

Educa. (2017). Minería y alternativas de defensa. Guía informativa. Recuperado de https://www.educaoaxaca.org/wp-content/uploads/2009/10/mineria_guia.pdf

Fortuna Silver Mines Inc. (2019). Technical Report. Vancouver: Fortuna Silver Mines Inc. Recuperado de https://www.fortunasilver.com/site/ assets / files/4097/san-jose-mine-technical-report-effective-date-february-22-2019-28mar19.pdf

Gamboa, G. (2006). Social multi-criteria evaluation of different development scenarios of the Aysén region, Chile. Ecological Economics (59), 157-170. Recuperado de https://ideas.repec.org/a/eee/ecolec/v59y2006i1p157-170. html

Garmedia, E., y Stagl, S. (2010). Public participation for sustainability and social learning: concepts and lessons from three case studies in Europe. Ecological Eocnomics, 69(8), 1712-1722. doi: https://doi.org/10.1016/j.ecolecon.2010.03.027

Global Witness. (2020). Defending tomorrow. Recuperado de https://www. globalwitness.org/en/campaigns/environmental-activists/defending-tomorrow/

Grupo México. (2019). Informe anual 2019. Recuperado de https: / /www.gmexico.com/GMDocs/ReportesFinancieros/Esp/2019/RF_ES_2019_IFN.pdf 
Gudynas, E. (2009). Diez tesis urgentes sobre el nuevo extractivismo. Contextos y demandas bajo el progresismo sudamericano actual. En Autor, Extractivismo, política y sociedad (pp.187-225). Quito, Ecuador: CAAP (Centro Andino de Acción Popular) y CLAES (Centro Latino Americano de Ecología Social). Recuperado de http://www.gudynas.com/publicaciones/GudynasNuevoExtractivismo10Tesis09x2.pdf

Gudynas, E. (2015). Extractivismos. Ecología, economía y política de un modo de entender el desarrollo y la naturaleza. Bolivia: CEDIB.

Gudynas, E. (2017). Extractivismos y corrupción en América del Sur. RevIISE, 10(10), 73-87. Recuperado de http://www.ojs.unsj.edu.ar/index.php/reviise/article/view/197

Gudynas, E. (2018). Extractivismos: el concepto, sus expresiones y sus múltiples violencias. Papeles de Relaciones Ecosociales y Cambio Global (143), 61-70.

Hernández, U. H. (2014). Vivir la mina: el conflicto minero en San José del Progreso y sus efectos cotidianos en la vida individual y la existencia colectiva. Rupturas, contrastes, reconstrucciones y resistencias (tesis de maestría). Centro de Investigaciones y Estudios Superiores en Antropología Social, Oaxaca, México.

Hernández, C. A. (11 de agosto de 2019). Pobreza en San José del progreso, el pueblo con una de las minas más ricas del mundo. El Imparcial. Recuperado de https://imparcialoaxaca.mx/los-municipios/341491/pobreza-en-san-jose-del-progreso-el-pueblo-con-una-de-las-minas-mas-ricas-del-mundo/

Martínez, J., Munda, G., y O’Neill, J. (1998). Weak comparability of values as a foundation for ecological economics. Ecologica Economics (26), 277-286. doi: https: / /doi.org/10.1016/S0921-8009(97)00120-1

Monterroso, I., Binimelis, R., y Rodríguez, B. (2011). New methods for the analysis of invasion processes: multi-criteria evaluation of the invasion of Hydrilla verticillata in Guatemala. Journal of Environmental Management, 92(3), 494-507. doi: https:// doi.org/10.1016/j.jenvman.2010.09.017

Movimiento Mesoamericano contra el Modelo Extractivo Minero. (8 de mayo de 2015). A 6 años del desalojo violento en San José del Progreso, el proyecto minero continúa expandiéndose. Recuperado de https://movimientom4.org/2015/05/a-6-anos-del-desalojo-violento-en-san-jose-del-progreso-el-proyecto-minero-continua-expandiendose/

Olivera, B. A. (2018). El fondo para las entidades federativas y municipios productores de hidrocarburos. En B. A. Olivera y A. de la Fuente (coords.), Anuario 2017. Las actividades extractivas en México: minería e hidrocarburos hacia el fin del sexenio (pp. 93-110). México: Fundar y Centro de Análisis e Investigación, A. C. Recuperado de https://fundar.org.mx/mexico/pdf/ AnuarioExtractivas2017.pdf

OXFAM. (2018). Minería y privilegios. Captura política y desigualdad en el acceso a los bienes comunes naturales en México: estudio de caso sobre San José del Progreso Oaxaca. Ciudad de México: OXFAM.

Ramos-Leal, J. A., Silva, F. O. T., y Montes, I. S. (2012). Analysis of aquifer vulnerability and water quality using SINTACS and geographic weighted regression. Environmental Earth Sciences, 66(8), 2257-2271. 
Ruiz, M., Sayer, J. A., y Cohen, S. (1993). El extractivismo en América Latina. Conclusiones y recomendaciones del Taller UICN-CCE. Amacayacu, Colombia: Unión Internacional para la Conservación de la Naturaleza.

S\&P Global Market Intelligence. (2019). World Exploration Trends 2019. Recuperado de https://pages.marketintelligence.spglobal.com/world-exploration-trends-2019-report-WS-0320.html

Secretaría de Desarrollo Agrario, Territorial y Urbano (SEDATU). (2017). Fondo para el Desarrollo Regional Sustentable de Estados y Municipios Mineros. Ciudad de México: SEDATU.

Secretaría de Desarrollo Social (SEDESOL). (2010). Informe anual sobre la situación de pobreza y rezago social. Recuperado de https://www.gob.mx/cms/ uploads/attachment/file/34405/Oaxaca_072.pdf

Secretaría de Desarrollo Social (SEDESOL). (2016). Informe anual sobre la situación de pobreza y rezago social 2016. Recuperado de http://diariooficial. gob.mx/SEDESOL/2016/Oaxaca_072.pdf

Secretaría de Desarrollo Social (SEDESOL). (2021). Catálogo de localidades (Base de datos). Recuperado de http://www.microrregiones.gob.mx/catloc $/$ LocdeMun.aspx?tipo=clave\&campo=loc\&ent $=21 \&$ mun $=043$

Secretaría de Economía (SE). (2018). Prontuario. Industria minero-metalúrgica. México: SE.

Secretaría de Economía (SE). (2021). La Secretaría de Economía anuncia la cancelación del cargo de subsecretario de Minería a partir del $1^{\circ}$ de septiembre de 2020. Recuperado de https://www.gob.mx/se/es/articulos/la-secretaria-de-economia-anuncia-la-cancelacion-del-cargo-de-subsecretario-de-mineria-a-partir-del-1-de-septiembre-de-2020?idiom=es

Secretaría de Gobernación (SEGOB). (2013). Estudio de la minería en México. Un análisis comparado con Canadá. México: SEGOB.

Secretaría de Hacienda y Crédito Público (SHCP). (2021). Informes sobre la situación económica, las finanzas públicas y la deuda pública. Recuperado de https://www.finanzaspublicas.hacienda.gob.mx/es/Finanzas_Publicas/ Informes_al_Congreso_de_la_Union

Servicio Geológico Mexicano (SGM). (2019). Anuario estadístico de la minería mexicana, 2019. Recuperado de http://www.sgm.gob.mx/productos/pdf/ Anuario_2019_Edicion_2020.pdf

Servicio Geológico Mexicano (SGM). (2020). Anuario estadístico de la minería mexicana, 2019. Recuperado de SGM. http://www.sgm.gob.mx/productos/ pdf/Anuario_2019_Edicion_2020.pdf

Svampa, M. (2019). Las fronteras del neoextractivismo en América Latina: conflictos socioambientales, giro ecoterritorial y nuevas dependencias. Bielefeld: Bielefeld University Press, transcript. https://doi. org/10.14361/9783839445266

Téllez, I., y Azamar, A. (2021). La política de concesiones a los grupos mineros de México. Problemas del Desarrollo, 52(206), 35-59. doi: https://doi. org/10.22201/iiec.20078951e.2021.206.69714

Thaden, H. A. von, Robles, C., y Fuente, M. E. (2020). La actividad minera del siglo XX en el Valle de Oaxaca: riesgos de salud pública del hoy. Re- 
vista Internacional de Contaminación Ambiental, 36(1), 165-175. Recuperado de http://www.scielo.org.mx/scielo.php?script=sci_arttext\&pi$\mathrm{d}=\mathrm{S} 0188-49992020000100165$

Toledo, V. M. (2015). Ecocidio en México. La batalla final es por la vida. México: Grijalbo.

Valladares de la Cruz, L. R. (2018). El asedio a las autonomías indígenas por el modelo minero extractivo en México. Iztapalapa (85), 103-131. doi: http: // dx.doi.org/10.28928/revistaiztapalapa/852018/atc5/valladaresdelacruzlr

Villanueva, P. (2018). La mina que dividió a un pueblo. OXFAM. Recuperado de https://www.oxfammexico.org/historias/la-mina-que-dividi\%C3\%B3-un-pueblo

Villavicencio, J. M. (2013). Tierra y violencia en la Sierra Sur de Oaxaca, México. Historia y Memoria (6), 67-100. doi: https: / / doi.org/10.19053/20275137.1963

Zaremberg, G., Guarneros, V., Flores, G., y Torres, M. (2019). Conversing with Goliath: Hemerographic Database on Conflicts in Mining, Hydrocarbon, $\mathrm{Hy}$ droelectric and Wind-Farm Industries in Mexico. Recuperado de https:// observandoagoliat.com/base-de-datos/ 